\title{
Rise of Pilgrims on the Camino to Santiago: Sign of Change or Religious Revival?
}

\author{
Lluis Oviedo . Scarlett de Courcier . Miguel Farias
}

\begin{abstract}
There is a renewed interest amongst scholars in the practice of pil- grimage. Over the past two decades, pilgrim numbers have risen significantly, whilst forms of "implicit" or "alternative" spirituality have gained visibility and now coexist with organised religions, sometimes sharing the same ritualistic space. There is probably no better place to look at the coexistence of old and new forms of ritual expression than in the Camino to Santiago. To better understand the meanings attributed to this pilgrimage, we undertook a survey with over 470 pilgrims at various locations along the Camino. The findings confirm that individuals with various, often contrasting, motivations and expectations walk side by side on this pilgrimage route. We suggest that the results cannot be read simplistically as either confirming a "post-secularisation" trend or a religious revival.
\end{abstract}

Keywords Pilgrimage Á Religious revival Á Spirituality Á Religious

change

Introduction

A number of competing theories have been offered regarding why people go on pilgrimages, focusing on bodily, emotional and social dimensions. Turner's (1978)

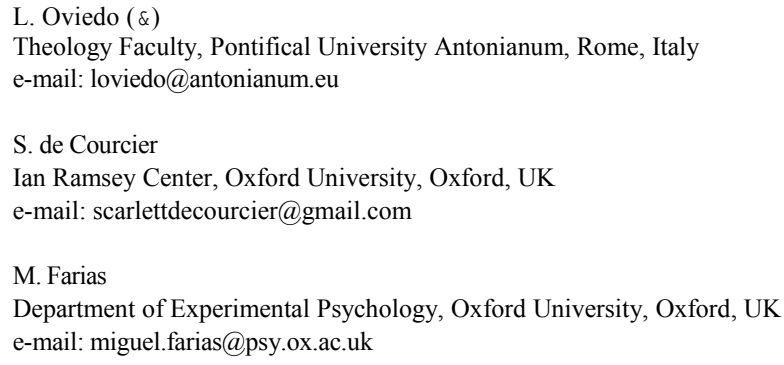


framing of pilgrimage according to the categories of communitas and liminality has been particularly influential. He suggests that the process of undertaking a sacred journey creates new forms of social interaction and experiences that move beyond the everyday world; this, he argues, can only be achieved by distancing oneself from one's familiar environment. More recently, other scholars have stressed the 'contesting' dimension of pilgrimage, that is, the ways in which this ritual is often displaced to the margins of organised religion and institutional social structure (Eade and Sallnow 1991; Coleman and Eade 2004).

A common criticism of both of these approaches is that not all pilgrimages can be placed within the same framework; indeed many traditional pilgrimages to religious shrines tend to confirm and re-enact forms of conventional religiosity. Recent work has opened up the heuristic toolbox to a variety of sacred journeys. These have included differentiating between institutional religions and new spiritualities (Ivakhiv 2003; Reader 2007; Steil and de Sa ' Carneiro 2008); community and individualism (Bilu 1988; Coleman 2002; Ivakhiv 2003; Sean 2003); religious and secular aspects (Graham and Murray 1997; Santos 2002; Swatos 2009; Timothy and Olsen 2006; Frey 1998; Margry 2008); and between tradition and innovation (Swatos 2009; Pack 2010). Other researchers have attempted to deconstruct the concept of pilgrimage by highlighting its overlap with 'tourism' - after all, what are these but forms of travel? (Morinis 1992; Santos 2002; Swatos and Tomasi 2002; Badone and Roseman 2004; Timothy and Olsen 2006).

Several theoretical frameworks may be applied to try to make sense of this ritual activity. 'Rational Choice theory' suggests that actions are driven by cost- benefit analysis; human ethology may explore 'appetitive behaviours' bringing pilgrims to the 'consummatory end act' of prayer at the end of the long journey (Feierman 2009); cognitive-adaptive religious theory may identify costly religious practices prompting group cohesion and pro-social behaviours (Sosis and Alcorta 2003; Nordin 2011; Kantner and Vaughn 2012). In a similar fashion, cultural anthropology may perceive a long pilgrimage as an "in-group marker" (McElreath et al. 2003).

The present work addresses the ongoing debate on whether the rise of pilgrims represents a 'religious revival', a secular or 'post-secular' expression of nature travel, or if it forms part of a wider movement of eclectic and 'fuzzy' spirituality (Hill et al. 2000; Marler and Hadaway 2002; Heelas et al. 2005). The Santiago Way is probably the most interesting pilgrimage route to test these three competing ideas. Although historically this has been a penitential track used to fulfil religious promises, the extraordinary rise of pilgrims in the last twenty years (see Fig. 1) ${ }^{1}$ contradicts a general decline in religious practice (Hervieu-Leger 1997). Specif- ically, the aim of the research was to assess pilgrims' motivations to undertake this journey, typically lasting two to four weeks, through a quantitative survey. Additionally, we also collected qualitative data on personal narratives about the pilgrimage.

${ }^{1}$ See also: http://peregrinossantiago.es/eng/pilgrims-office/statistics/?anio=2012\&mes=9. 


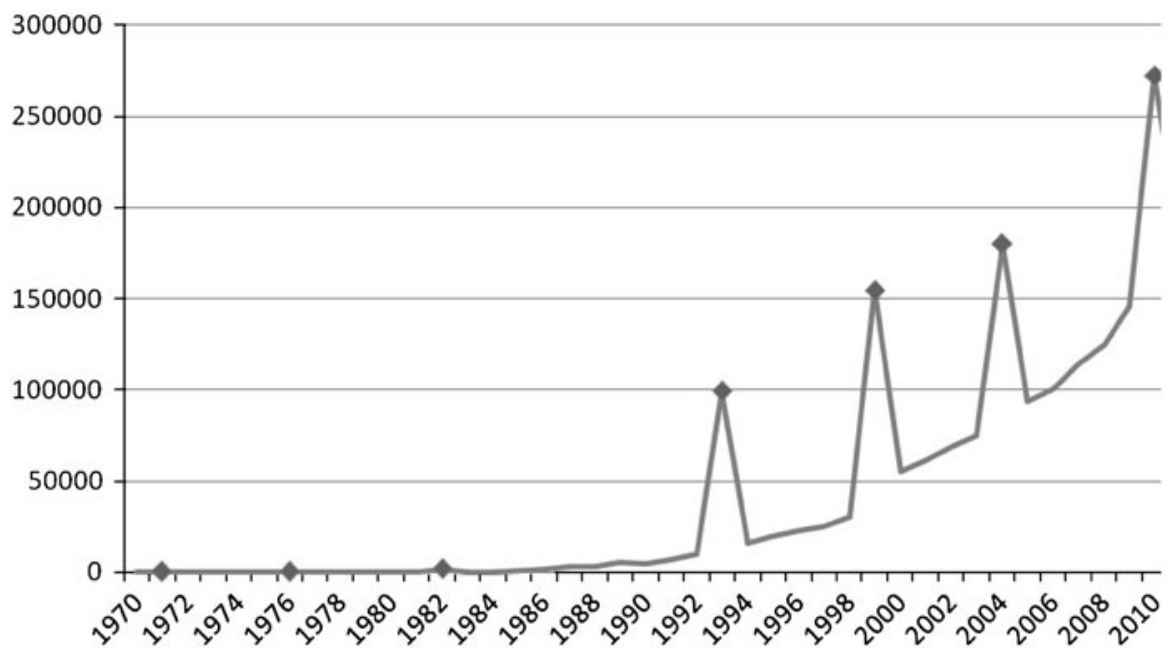

Fig. 1 Evolution of the number of pilgrims to Santiago. Filled diamond Holy Jacobean year. Source: statistics archive Cathedral of Santiago

Method and Data Collection

The first section of the questionnaire included a list of 48 religious and secular items describing motivations to be on the pilgrimage. Pilgrims ranked their levels of agreement with these items on a Likert scale (1-6). This list of motivations was developed taking into account the available literature (e.g. Graham and Murray 1997; Coleman 2002) as well as speaking to people who had done the Santiago way. The questionnaire also included sections on demographics; duration and type of pilgrimage (alone or part of a group); levels of religious practice and experience; and two openended questions about 'expectations' and 'religious or spiritual experiences' during the pilgrimage. The questionnaire was originally written in English and then translated into four additional languages (Spanish, French, Portuguese and German).

There are several pilgrim trails, though the Camino France or 'French way' is 's the most popular. The Camino France forms the spine of the Camino de Santiago, 's stretching $780 \mathrm{~km}$ from St Jean Pied du Port in France to Santiago de Compostela in North-West Spain. An efficient infrastructure of refuges and hostels provides cheap accommodation and most pilgrims use these facilities to rest. The surveys were handed out to pilgrims at such places, usually after the daily walking time was over.

A total of 470 questionnaires were collected along the Camino France during 's August-September of 2009, and July 2010. Interviews were also conducted with many pilgrims, as well as hospitaleros (those responsible for pilgrims' accom- modation) and Catholic priests who attended to pilgrims' religious or spiritual needs. 
The demographic data of the present sample describes a varied population of more than 40 nationalities (including 30.4 \% Spanish, $17.7 \%$ German, $6.8 \%$ American, $5.9 \%$ Italian, $5.2 \%$ French and $5 \%$ Brazilian). The average age of pilgrims was 32.2 years, with a standard deviation of $14.5 ; 51.1 \%$ were male. About one third were students.

\section{Religiosity Indicators}

Two thirds of the sample group were Christian (66\%), while $22.6 \%$ were atheists. Those describing themselves as spiritual or New Agers had a marginal represen- tation $(2.3 \%)$. The remaining participants either belonged to 'other' religions or did not indicate their religious or secular affiliation.

One of the main aims of the research was to assess levels of secularisation on the Camino. Many voices, especially those of Catholic authorities, have expressed concern about the decline of religious practice and the ever-increasing secular profile of pilgrims who, generally, lack interest in the specifically Catholic elements of the pilgrimage. A number of items in the survey were used to assess religious practice throughout the journey. When asked which religious aspects of the Camino pilgrims were most drawn to, the main answers were: 'Private prayer or contemplation' (31.8\%); 'Prayer/reflection with others' (14.8\%); and 'Religious rituals/sites' (15\%).

Concerning other religious indicators, $24.7 \%$ of pilgrims pray at least once a day, and $23.4 \%$ attend religious services at least once a week. Comparing these figures for the Spanish pilgrims $(\mathrm{N}=134)$ with the latest data provided by European Surveys regarding Spain (ESS 2010), $18.4 \%$ of pilgrims pray daily, against $20.9 \%$ of the general population surveyed in ESS; $20 \%$ of pilgrims attend weekly religious services, while the general sample from the ESS gives a figure of $14.4 \%$. These results seem to suggest that there is not a vast difference between the general population and pilgrims. From this perspective it seems that the Camino does not draw a specific type of person from the general population - the most religious, for example — but rather a representative subset of the general population; no more, and no less, religious than average. Although religious practice during the pilgrimage may seem low, these results are in line with the current statistics of religiosity in most European societies.

Observing reported levels of religiosity and spirituality sheds some light on the impact of secularisation. The mean religiosity level (on a scale from 0 to 10) was 3.97 $(\mathrm{SD}=2.93)$, whilst the mean for spirituality ('How spiritual are you?') was 5.9 (SD = $2.85)$. This suggests that pilgrims tend to identify themselves more with spirituality than religiosity.

The questionnaire included seven items concerning religious experiences, e.g. 'I have felt very close to God/the divine in prayer or meditation' or 'I have been aware of God's/the divine's presence'. Only the latter item reaches a mean of $3(\mathrm{SD}=1.9)$ (on a six-point scale), while the remaining items score between 2 and 3 points. The impression arising from these results is that pilgrims, on average, do not report a high frequency of religious experiences. 
Thus far the results suggest that pilgrims on the Santiago Way are not any more or less religious than non-pilgrims. We now turn to the analysis of motivations.

Analysing the Motivations

The survey listed 48 possible motivations to go on pilgrimage that participants were asked to rank in order of importance. Using exploratory factor analysis with Varimax rotation, we extracted six factors which explained $54 \%$ of the total variance. The factors were: religious growth, spiritual growth, sensation seeking, seeking life direction, community, and religious devotion (see Tables 1, 2).

The factor analysis distinguishes between dimensions that are very often entrenched, as in the case of religiosity and spirituality motivations. Religious Growth clusters items that are fitting of a traditional religious mentality (e.g. 'Grow in faith', 'Be closer to God'). The overall mean for this type of motivation was not high: $3.09(\mathrm{SD}=1.37)$ on a scale of 1 to 6 . This result draws doubts regarding a religious revival in the Camino. The second factor, Spiritual Growth, also consisted of six items that directly tapped into a more secular and vague form of religiosity (e.g. 'Expand my consciousness' or 'Find my deeper self'). This factor had the highest average of all motivations $(4.03, \mathrm{SD}=1.19)$. This reveals a greater interest in a secular spirituality and confirms the scores of religious and spiritual self-assessment. Further, the low score $(1.88, \mathrm{SD}=1.11)$ on the sixth factor, labelled Religious Devotion, which describes traditional pilgrimage motivations (e.g. 'Fulfilling a promise' or 'Repentance'), indicates that what moves modern pilgrims to the Camino is quite different from their premodern ancestors.

The Sensation Seeking factor, which overall score was the second highest (3.17, SD $=1.18$ ), reflects a clearly secularised pattern, potentially associated with qualities of 'personal expressivism' (Taylor 2007), such as 'Testing my limits' or 'Proving myself; 'Search of adventure'; 'Enjoying myself. Likewise, Seeking life direction captures a similar individualistic dimension. On the other hand, Community includes three items, which partially overlap with a sense of religious collectiveness and duty of helping others (e.g. 'Doing something on behalf of someone').

These results show that overall pilgrims gravitate towards a spiritual sensitivity, though there is also space for more traditional religious motivations. The analysis of correlations between the various factors, age and religious practice confirms the differences between religious and spiritual motivations (see Table 3). As expected, frequency of religious practice is strongly correlated with "religious growth" but only weakly with "spiritual growth". Further, the expressivistic motivations of "sensations seeking" is negatively correlated with "religious growth" but positively correlated with "spiritual growth". Further, we also notice that "religious growth" and religious practice are positively correlated with age, showing that the older pilgrims tend to be more traditionally religious. Older people are also less interested in seeking new experiences and in "looking for life direction".

\section{Constructing Personal Narratives}

The survey data can be further explored by looking at the relevance of individual items. For example, the 'Hope of meeting a partner' $(\mathrm{M}=1.63 ; \mathrm{SD}=1.1)$ 
Table 1 Santiago pilgrims survey-factor description
Factor 1 Religious growth $($ Cronbach's alpha $=.921)$

Be closer to God

Strengthen my religious/spiritual beliefs

Learning about God by being with other people

Having more time for prayer

Grow in faith

Find out more about my religion/spirituality

Drawing strength from a sacred place

Pray for the healing of others

Paying reverence to a saint or sacred space

Factor 2 Spiritual growth (Cronbach's alpha $=.862$ )

Find myself

Expand my consciousness

Find my deeper self

Being close to nature

Find peace

Purifying my spirit

Yearning for a simple life

Seeking unity with the universe

Factor 3 Sensation seeking (Cronbach's alpha $=.871$ )

Curiousity

Testing my limits

Doing something different

Proving myself

Search for adventure

Enjoying myself

See interesting sights

Getting to know people

Factor 4 Seeking life direction $($ Cronbach's alpha $=.824)$

Trying to know the future

Coming to terms with a decision

Seek guidance for the future

To look for a sign or direction in my life

Factor 5 Community (Cronbach's alpha $=.702$ )

Doing something on behalf of someone

Helping sick people

Being with my community

Factor 6 Religious devotion (Cronbach's alpha $=.726$ )

Fulfilling a promise

Fulfilling a religious duty

Repentance 
Table 2 Means of six main factors (1-6)

\begin{tabular}{llll}
\hline & N & Mean & SD \\
\hline f1 Religious growth & 435 & 3.0907 & 1.37899 \\
f2 Spiritual growth & 442 & 4.0326 & 1.19760 \\
f3 Sensations seeking & 451 & 3.9092 & 1.18769 \\
f4 Seeking life direction & 453 & 3.1720 & 1.41581 \\
f5 Community & 446 & 2.7443 & 1.28367 \\
f6 Devotion & 422 & 1.8832 & 1.11898 \\
\hline
\end{tabular}

Table 3 Pearson correlation coefficients between factors, age, and religious practice $(\mathrm{N}=453)$

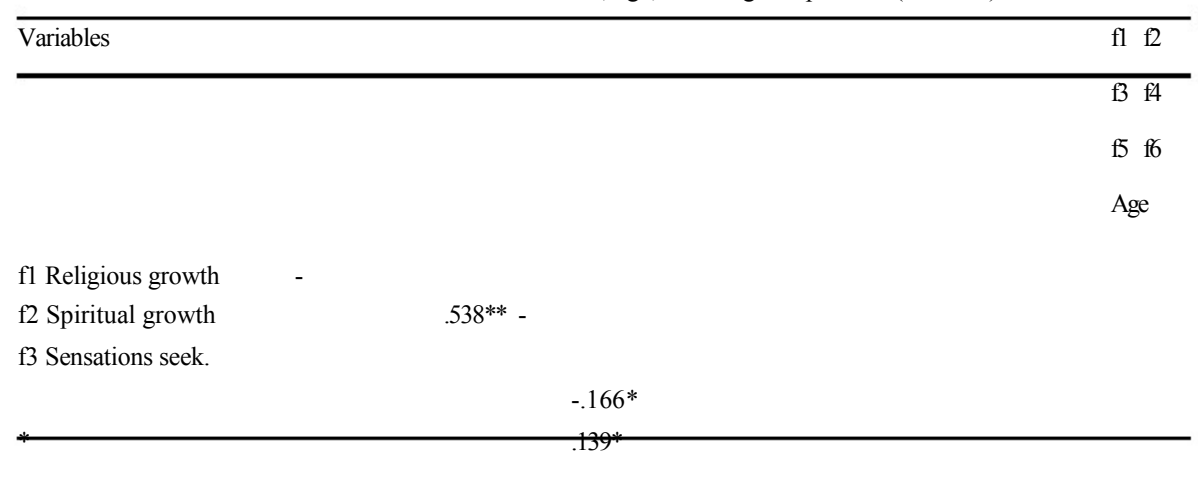

\section{f4 Life direction}

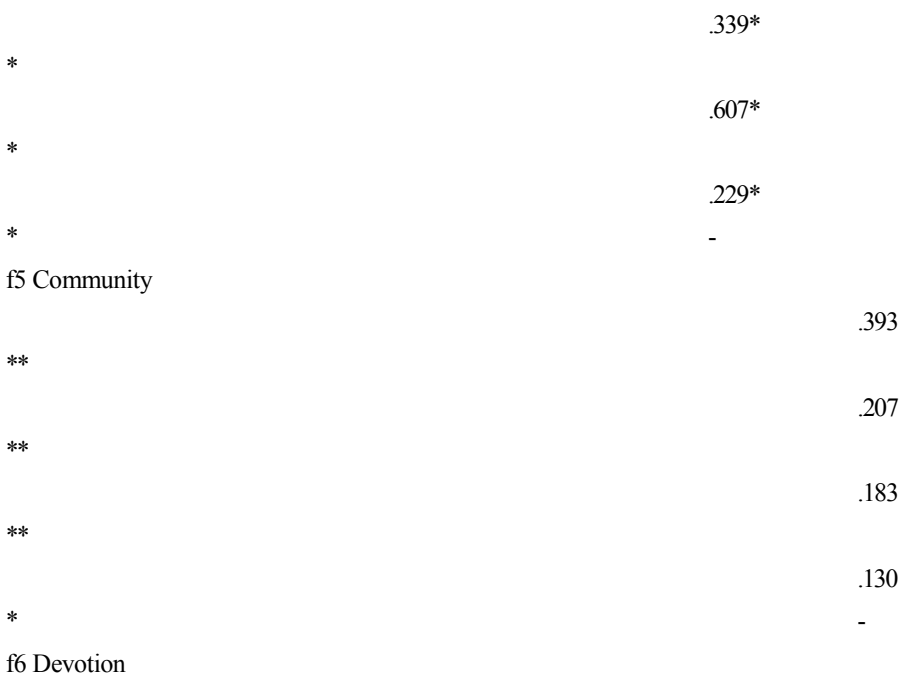

$1 *$ 
revealed that this was a very low priority to go on pilgrimage. On the other hand, other seemingly frivolous motives such as 'Enjoying myself', were a high motivation $(\mathrm{M}=$ 4.3; $\mathrm{SD}=1.51$ ).

Despite the high scores for secular and individualistic motivations, many of the results reveal the appeal of moving away from an ordinary experience of life. The items with the highest scores highlight this: 'To be close to nature' $(\mathrm{M}=4.89 ; \mathrm{SD}=1.23)$ and 'To find my deeper self' $(\mathrm{M}=4.80 ; \mathrm{SD}=1.37)$. In both cases, the meaning of the pilgrimage seems related to an almost mystical sense of nature - a desire to recover a sense of identity through a detachment from everyday life and relationships. In this sense, the secularisation of the Camino cannot be framed as a straightforward 'desacralisation' or 'disenchantment' of the world. Being in nature allows for a deeper sense of connection with the self - the self which the pilgrim is wrestling with, either in search of a new direction or of finding a deeper, more connected and peaceful structure. Thus, nature could be perceived as a conduit to a 're-routing of the self', a dimension in which the personal self might be lived in its most pristine form and rescued from estrangement (Taylor 1992).

We now turn to the testimonies. Two questions invited pilgrims to write about their expectation of the Camino, and their religious or spiritual experiences, and reactions, to the pilgrimage. These were some of the accounts, which highlight the coexistence of religious, spiritual and secular themes: 
- My expectations are to dialogue with God, to ask for help; to take part in mass; praying for other people. My experiences: sadness, weeping in a Church; "feeling supported by God".

- I have had some incredible dreams and beautiful experiences. I've felt energy, smelt incense in the desert, felt connections with others.

- I walk in surrender and strengthen my belief that the universe is always there to support me. People are like angels to each other in life, we are being used by 'the force'. Everything happens 'through' us. In stillness, I feel that everything is united and connected. The universe speaks to me in symbols. I feel humble and so grateful to be here.

- Being in nature and getting regular exercise makes me feel very happy and emotionally very positive.

- After 12 years in a relationship, my partner dropped me a month ago. I thought it was the end of my life. The only solution I found was the Camino. I wanted to heal the pain in my soul. I wanted to close the gate in my relationship and to stop loving him. Several times a day, I've visited church and prayed. And I cried most of the time I was in churches. Slowly, I found myself full of grace and peace. My vision is now clear; I reckon I am over him.

- My expectations are to get on with others. Sharing and listening to their stories and life events. Supporting and helping them by being attentive. Having fun, chatting and enjoying the company of others.

- I want to show God and the Apostle Santiago my love and devotion for them and, in this way, by doing the Camino, to thank them for the family they gave me, the health we enjoy, and to ask to keep blessing us.

In these accounts, the experience of pilgrimage is eminently plural. The Camino allows for the construct of narratives that follow particular motivations.

\section{Drawing Conclusions}

Returning to our major question - is the rise of pilgrims on the Camino a 'religious revival', a secular or 'post-secular' expression of nature travel, or if it forms part of a wider movement of eclectic and 'fuzzy' spirituality? It is safe to exclude the first one. Our data clearly indicate that the majority of pilgrims are not particularly interested in traditional religiosity. However, it is difficult to read the results as a clear sign of spiritual change. There are clear signs of the presence of eclectic forms of spirituality, but this is associated with a desire or search for new sensations. We suggest framing the results by considering two major types of pilgrims, roughly corresponding to what Taylor (2007) described as the 'porous' and the 'buffered' self. While the first refers to the individual integrated into a cosmos of religious meanings and values, the 'buffered self' corresponds to the modern person, flexible and adaptive to every context, without being integrated or subsumed into a greater cosmos of meaning. The Camino provides a context in which both types coexist: one integrated into a religious universe of symbols, and the second constructing her own universe of meaning and references, not immediately connected with a 
predetermined framework, but vaguely or fuzzily attaching itself to experiences and feelings. The second kind of pilgrim is predominant in our sample.

Many pilgrims seem to be looking for an experience outside the margins of material interest and the simplistic pursuit of gain. In this sense, pilgrimage offers something almost unique in the context of advanced societies and their logic of consumerism. In Weberian terms, it offers an 'escape from the iron cage', or an avoidance of the impoverishing logic of disenchantment. Following Taylor (2007), we suggest that the pilgrimage experience forms part of the process through which individuals in advanced societies try to redefine their flexible identities.

\section{References}

Badone, Ellen, and Sharon R. Roseman. 2004. Intersecting journeys: The anthropology of pilgrimage and tourism. Chicago: University of Illinois Press.

Bilu, Yoram. 1988. The inner limits of communitas: A covert dimension of pilgrimage experience. Ethos 16(3): 302-325.

Coleman, Simon. 2002. Do you believe in pilgrimage? Communitas, contestation and beyond. Anthropological Theory 2(3): 355-368.

Coleman, Simon, and John Eade (eds.). 2004. Reframing pilgrimage: Cultures in motion. London: Routledge.

Eade, John, and Michael J. Sallnow (eds.). 1991. Contesting the sacred: The anthropology of christian pilgrimage. London and New York: Routledge.

Feierman, Jay R. 2009. Conclusion. In The Biology of religious behavior: The evolutionary origins of faith and religion, ed. Jay R. Feierman, 243-264. Santa Barbara, CA: Praeger/ABC-CLIO.

Frey, Nancy Louise. 1998. Pilgrim stories: On and off the road to Santiago. Berkeley: University of California Press.

Graham, Brian, and Michael Murray. 1997. The spiritual and the profane: the pilgrimage to Santiago De Compostela. Cultural Geographies 4(4): 389-409.

Heelas, P., L. Woodhead, B. Seel, B. Szerszynski, and K. Tusting. 2005. The Spiritual revolution: Why religion is giving way to spirituality. Malden MA, Oxford: Wiley, Blackwell.

Hervieu-Leger, Daniele. 1997. Le pelerin et le converti La religion en mouvement. Paris: Flammarion.

Hill, P.C., K.I. Pargament, R.W. Hood, M.E. McCullough Jr, J.P. Swyers, D.B. Larson, and B.J. Zinnbauer. 2000. Conceptualizing religion and spirituality: Points of commonality, points of departure. Journal for the Theory of Social Behaviour 30: 51-77.

Ivakhiv, Adrian. 2003. Nature and self in New Age pilgrimage. Culture and Religion 4(1): 93-118.

Kantner, John, and K.J. Vaughn. 2012. Pilgrimage as costly signal: Religiously motivated cooperation in Chaco and Nasca. Journal of Anthropological Archaeology 31(1): 66-82.

Margry, Peter Jan. 2008. Shrines and pilgrimage in the modern world: New itineraries into the sacred. Amsterdam: Amsterdam University Press.

Marler, P.L., and C.K. Hadaway. 2002. "Being religious" or "being spiritual" in America: A zero-sum proposition? Journal for the Scientific Study of Religion 41: 289-300.

McElreath, Richard, Robert Boyd, and Peter J. Richerson. 2003. Shared norms and the evolution of ethnic markers. Current Anthropology 44(1): 122-130.

Morinis, Alan. 1992. Sacred journeys: The anthropology of pilgrimage. Westport, London: Greenwood. Nordin,

Andreas. 2011. The cognition of hardship experience in Himalayan pilgrimage. Numen 58 632-673.

Pack, Sasha D. 2010. Revival of the pilgrimage to Santiago de Compostela: The politics of religious, national, and European patrimony, 1879-1988. The Journal of Modern History 82(2): 335-367.

Reader, Ian. 2007. Pilgrimage growth in the modern world: Meanings and implications. Religion 37(3): 210-229.

Santos, Xose M. 2002. Pilgrimage and tourism at Santiago de Compostela. Tourism Recreation Research 27(2): 41-50.

Sean, Slavin. 2003. Walking as spiritual practice: The pilgrimage to Santiago de Compostela. Body \& Society 9(3): 1-18. 
Sosis, Richard, and Candace Alcorta. 2003. Signaling solidarity and the sacred: The evolution of religious behavior. Evolutionary Anthropology 12: 264-274.

Steil, Carlos Alberto, and Sandra de Sa Carneiro. 2008. Peregrinac o, turismo e Nova Era: Caminhos de ,a

Santiago de Compostela no Brasil. Religiao e Sociedade, Rio de Janeiro 28(1): 105-124.

Swatos, William H. 2009. Pilgrimage and conversion. Religion and the Social Order 17: 115-130.

Swatos, William H., and Luigi Tomasi (eds.). 2002. From medieval pilgrimage to religious tourism: The social and cultural economics of piety. Santa Barbara, CA, Denver, CO: Praeger.

Taylor, Charles. 1992. The ethics of authenticity. Cambridge, MA.: Harvard University Press. Taylor, Charles. 2007. A secular age. Cambridge, MA.: Harvard University Press.

Timothy, Dallen J., and Daniel H. Olsen. 2006. Tourism, religion and spiritual journeys. London, New York: Routledge.

Turner, Victor, Edith Turner, Deborah Ross (1978) 2011. Image and pilgrimage in christian culture, New York: Columbia University Press. 